\title{
Analysis of Germanium Hydride Molecular Clusters
}

\author{
Andrzej J. Gorączko
}

Department of Inorganic Chemistry, University of Technology and Life Science, Seminaryjna 3, 85-326, Bydgoszcz, Poland

\begin{abstract}
Isotope clusters in library electron ionization mass spectra of germanes often appear a few $u$ lower than theoretically expected from elemental composition; for example, the dominant peak of the $\mathrm{Ge}_{4} \mathrm{H}_{10}{ }^{+}$pattern is shifted $8 \mathrm{u}$ down. This phenomenon is due to combinations of three essential components: the molecular ion $\mathrm{Ge}_{n} \mathrm{H}_{2 n+2}{ }^{+}$and two products of hydrogen elimination, $\mathrm{Ge}_{n} \mathrm{H}^{+}$and $\mathrm{Ge}_{n}{ }^{+}$. Using these components, isotope clusters can be accurately projected for germanium hydrides from $\mathrm{Ge}_{2} \mathrm{H}_{6}$ up to $\mathrm{Ge}_{5} \mathrm{H}_{12}$.
\end{abstract}

Key words: Germanium hydrides, Molecular clusters, Isotopomeric analysis

\section{Introduction}

$\mathrm{T}$ he mass spectra of organometallic derivatives display, in high abundance, fragment ions that retain the metal element. These ions can be identified due to the distinct isotopic composition of the higher elements that are known to have significant natural abundances. An even more complex pattern often results from ions that differ in chemical composition by only one or two hydrogens [1], as is often the case for compounds containing alkyl groups bonded directly to the metal element. In such cases, the use of high-resolution mass spectrometry and the careful analysis of peak intensities becomes essential in order to fully elucidate the fragmentation patterns. Mass spectrometry seems to be an effective method for the identification and investigation of Ge compound structures due to the characteristic isotopic distribution pattern at 70-76 $\mathrm{u}$. The occurrence of germanium atoms leads to complex isotopomeric clusters in mass spectra and a shift in the most abundant peak in the ionic pattern, particularly for compounds containing more than one germanium atom in the molecule. The location of the most abundant peak of the isotopomeric cluster (LAPIC) [1] is difficult to predict for these ions, especially for species containing several germanium atoms.

Correspondence to: Andrzej J. Gorączko; e-mail: andygor@utp.edu.pl, uklejna@interia.pl
Some interesting features of germanium and germanes can be found in the literature. Martin and Schaber [2] obtained the mass spectra of germanium clusters. They found that the intensity of the $\mathrm{Ge}_{\mathrm{n}}{ }^{+}$ion cluster decreases above $n=6$ and again above $n=10$. Gingerich's studies $[3,4]$ of the thermodynamic properties of group IV element clusters provided the atomization energies and enthalpies of formation of $\mathrm{Ge}_{2}$ to $\mathrm{Ge}_{8}$. These parameters were obtained from mass spectrometric equilibrium data measurement. Germanium in hydrides was revealed to be not only four-coordinated but to sometimes form only two bonds in linear chain or cyclic structures. The planar digermene $\mathrm{H}_{2} \mathrm{Ge}=\mathrm{GeH}_{2}$ form is the transition state in the interconversion of the germylgermylene $\mathrm{H}_{3} \mathrm{Ge}-\mathrm{GeH}$ structure, which was found to correspond to minimum enthalpy [5]. Theoretical and experimental investigations [6] indicate that $\mathrm{Ge}_{3}$ and $\mathrm{Ge}_{4}$ clusters have cyclic structures. Germanium also forms several compounds with 3D cyclic structures [7, 8], such as tetragermatetrahedrane $\left(\mathrm{Ge}_{4} \mathrm{H}_{4}\right)$, hexagermaprismane $\left(\mathrm{Ge}_{6} \mathrm{H}_{6}\right)$, octagermacubane $\left(\mathrm{Ge}_{8} \mathrm{H}_{8}\right)$, dipentagermaprismane $\left(\mathrm{Ge}_{10} \mathrm{H}_{10}\right)$, octagermaprismane $\left(\mathrm{Ge}_{8} \mathrm{H}_{8}\right)$, and polygermanes.

\section{Mass Spectral Features of Germanium Hydrides}

The first studies of germanium hydrides were mass spectrometric studies of simple hydrides [9, 10] performed 
by Saalfeld and Svec. Germanium tetrahydride commonly decomposes in the following manner (Equation 1) [11]:

$$
\begin{aligned}
\mathrm{GeH}_{4} & \rightarrow \mathrm{GeH}_{3}+\mathrm{H} \rightarrow \mathrm{GeH}_{2}+2 \mathrm{H} \rightarrow \mathrm{GeH}+3 \mathrm{H} \\
& \rightarrow \mathrm{Ge}+4 \mathrm{H},
\end{aligned}
$$

but the complex destruction of $\mathrm{GeH}_{4}$ is also possible via the reaction (Equation 2) [11]

$$
\mathrm{GeH}_{4} \rightarrow \rightarrow \mathrm{Ge}_{2-7} \mathrm{H}_{0-3}+\mathrm{yH} .
$$

The mass spectra of some higher hydrides such as $\mathrm{Ge}_{2} \mathrm{H}_{6}, \mathrm{Ge}_{3} \mathrm{H}_{8}$ and $\mathrm{Ge}_{4} \mathrm{H}_{10}$ have also been investigated [10]. Unlike $\mathrm{GeH}_{4}$, the digermane $\mathrm{Ge}_{2} \mathrm{H}_{6}$ and subsequent germanes exhibit reasonably intense molecular patterns. The identification of germanes can be a difficult task. The molecular clusters in the EI mass spectra from MS databases (derived experimentally) are located a few $u$ lower then the patterns theoretically expected from element contents (see, e.g., Figure 1). In the example below, the experimental pattern of pentagermane from the NIST MS database is shifted $12 \mathrm{u}$ down. The most abundant peak of the $\mathrm{Ge}_{2} \mathrm{H}_{6}$ molecular mass cluster (as provided by Riveros and Takashima) corresponds to $\mathrm{Ge}_{2} \mathrm{H}_{2}^{+}$, and the resulting abundances of the important fragment ions follow the order [12]:

$$
\mathrm{Ge}_{2} \mathrm{H}_{2}{ }^{+}>\mathrm{Ge}_{2} \mathrm{H}_{4}{ }^{+}>\mathrm{Ge}_{2}{ }^{+} \geq \mathrm{Ge}_{2} \mathrm{H}^{+} \geq \mathrm{Ge}_{2} \mathrm{H}_{6}{ }^{+} .
$$

Ricca and Bauschlinger [13] calculated the $\Delta H_{\mathrm{f}}$ values of ions formed progressively from digermane by hydrogen elimination, and found the following trend:

$$
\begin{aligned}
\mathrm{H}_{3} \mathrm{GeGeH}_{3}{ }^{+} & <\mathrm{H}_{3} \mathrm{GeGeH}_{2}{ }^{+}<\mathrm{H}_{2} \mathrm{GeGeH}_{2}{ }^{+}<\mathrm{H}_{2} \mathrm{GeGe}^{+} \\
& \cong \mathrm{GeHHGe}^{+} \cong \mathrm{HGeGeH}^{+}<\mathrm{H}_{2} \mathrm{GeGeH}^{+}<\mathrm{HGeGe}^{+} .
\end{aligned}
$$

The $\mathrm{Ge}_{2}^{+}$radical cation was also generated by pulsed laser vaporization [14]. A somewhat similar extensive fragmentation is observed for $\mathrm{Ge}_{3} \mathrm{H}_{8}$, with negligible formation of the molecular ion [4]. The base peak in this case corresponds to the $\mathrm{Ge}_{3}{ }^{+}$ion (relative abundance 100), while other important fragment ions have been identified as $\mathrm{Ge}_{3} \mathrm{H}^{+}, \mathrm{Ge}_{2} \mathrm{H}_{2}^{+}, \mathrm{Ge}_{2} \mathrm{H}_{4}^{+}$and $\mathrm{Ge}_{2}^{+}$. These results clearly

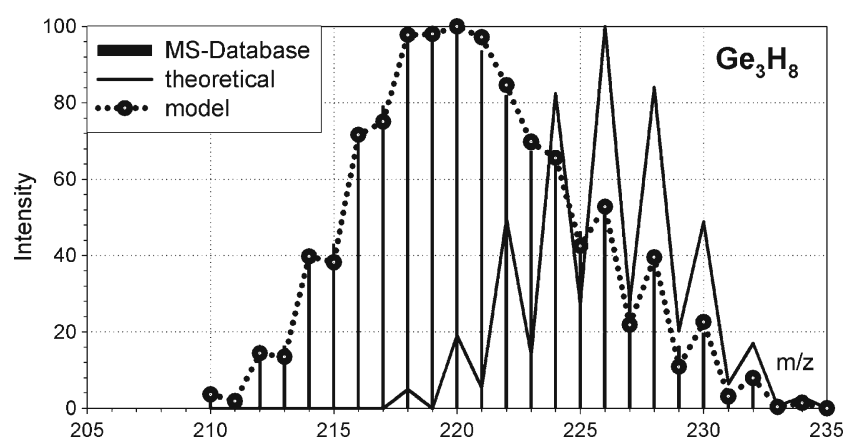

Figure 1. Modeling the molecular cluster of trigermane reveal the tendency for the mass spectra of higher hydrides to be dominated by ions with high metal contents resulting from the successive elimination of hydrogen molecules.

The mass clusters (obtained from MS databases) [15-18] of the molecular ions of simple germanium hydrides from $\mathrm{Ge}_{2} \mathrm{H}_{6}$ to $\mathrm{Ge}_{5} \mathrm{H}_{12}$ differ in peak locations and pattern forms from predictions based on ion formula and natural isotopic abundances. Why do such differences occur? What is the nature of this phenomenon? These questions await theoretical explanation. The present work undertakes a theoretical exploration of this question by modeling low-resolution isotopomeric clusters of the germanium hydride molecular ions from $\mathrm{Ge}_{2} \mathrm{H}_{6}$ to $\mathrm{Ge}_{5} \mathrm{H}_{12}$.

\section{Calculations of Molecular Cluster Contents}

The theoretical clusters were calculated by the molecular modeling of isotopomeric pattern (MMIP) method [1]. The locations and intensities of peaks were predicted from the formula of the ion and the natural abundances of the element isotopes, but the expected and experimental LAPIC parameters are significantly different.

The experimental molecular ion clusters of $\mathrm{Ge}_{2} \mathrm{H}_{6}, \mathrm{Ge}_{3} \mathrm{H}_{8}$, $\mathrm{Ge}_{4} \mathrm{H}_{10}$, and $\mathrm{Ge}_{5} \mathrm{H}_{12}$ were examined by isotopomeric modeling as complex patterns. The shifting of the main peaks suggests that the components are products of dehydrogenation. Shifting values indicate more advanced stages of the process of hydrogen elimination, such as $\mathrm{M}-\mathrm{H}, \mathrm{M}-\mathrm{H}_{2}$, or $\mathrm{M}-\left(\mathrm{H}_{2}+\mathrm{H}\right)$, as can be theoretically predicted [1].

The intensities of experimental peaks $P_{\text {exp.i }}$ located within the range $m_{1}$ to $m_{t}$ are compared $\left(P_{\exp } \leftrightarrow P_{\text {calc }}\right)$ with predictions [19] based on the molecular formula of the compound investigated and the corresponding natural isotope abundance (peaks with intensities of $P_{\text {calc.i }}$ positioned within the region $m_{1}$ to $m_{k}$ ):

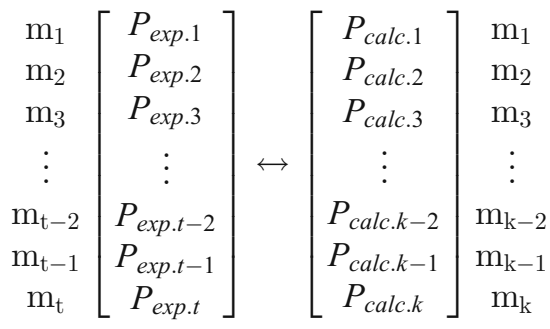

\section{Scheme 1}

The accordance level is estimated from peak intensities by the "theoretical" variance $s_{\text {theor }}^{2}$, calculated from the number of peaks $v$ that occur simultaneously among both the theoretical and experimental $\mathrm{m} / \mathrm{z}$ values:

$$
s_{\text {theor }}^{2}=\frac{1}{v} \sum_{i=1}^{v}\left(P_{\text {exp.i }}-P_{\text {calc. } . ~}\right)^{2}
$$

A high value of $s^{2}$ theor suggests that further modeling of the molecular pattern region is needed. The procedure 
applied is similar to that employed for dehydrogenation [1]; all of the ions in the range from $\mathrm{Ge}_{n} \mathrm{H}_{2 n+2}{ }^{+}$to $\mathrm{Ge}_{n}{ }^{+}$ are considered.
The modeling described here deals with compounds of formula $\mathrm{Ge}_{n} \mathrm{H}_{2 n+2}$, and the theoretical vector contains $k$ elements:

$$
\begin{aligned}
& |M| M-1|M-2||M-2 n| M-2 n-1|M-2 n-2|
\end{aligned}
$$

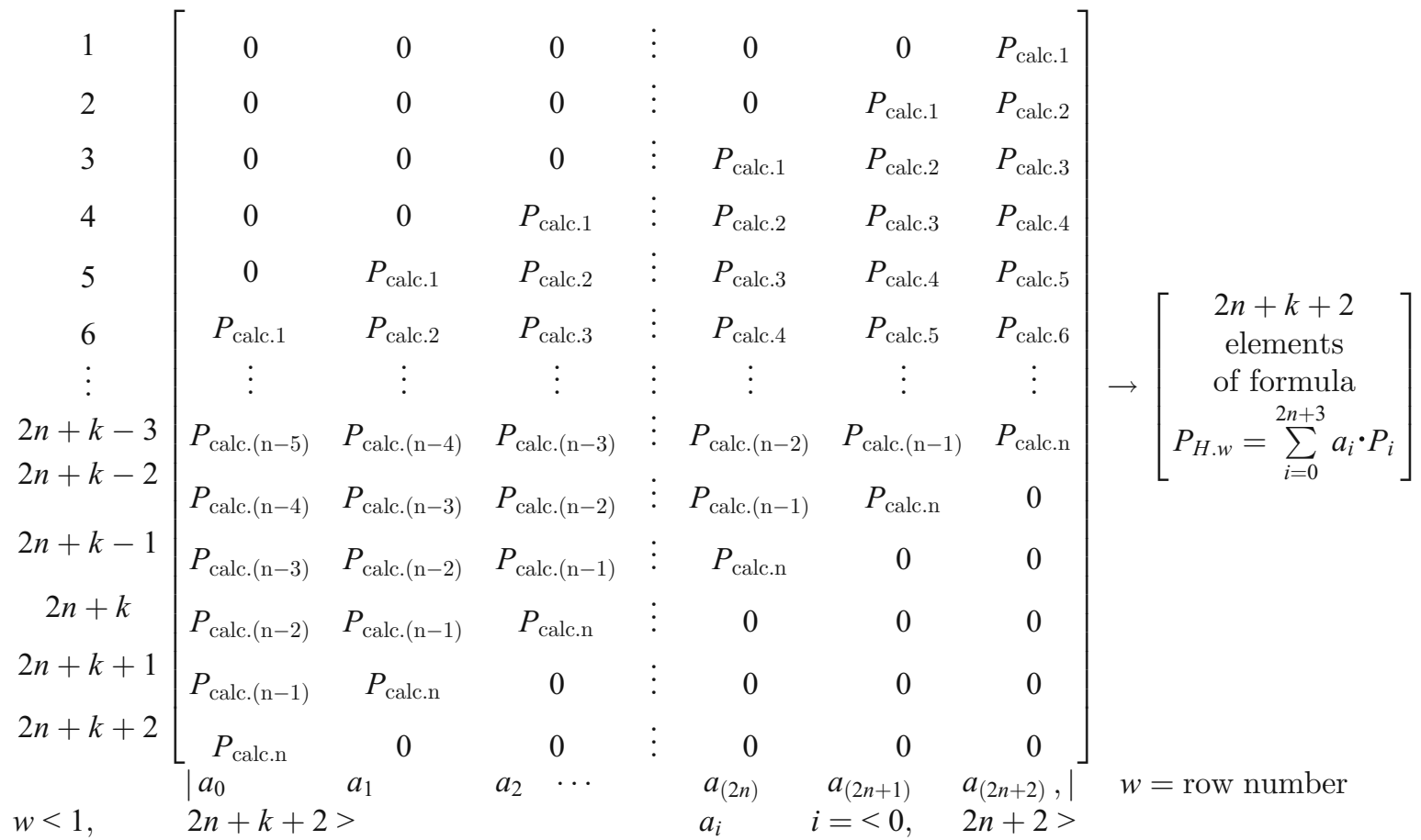

Scheme 2

1. The quasi-molecular cluster [1] is calculated with the aid of a working matrix with of $2 n+k+2$ rows and $2 n+3$ columns consisting of the following components:

- The real molecular pattern $M$ (theoretical band predicted from the formula and natural isotope abundance)

- The first stage of hydrogen radical loss $(\mathrm{M}-\mathrm{H})$

- The second step of hydrogen molecule loss $(\mathrm{M}-2 \mathrm{H})$

- The third step $(\mathrm{M}-3 \mathrm{H})$, and so on up to $2 n+2$ components

- The others, respectively.

Each column is filled with the isotopomeric cluster expected by the MMIP method [20] based on element contents and element isotopic abundances. Patterns of neighboring columns are shifted according to the mass of the ion considered. The ion $\mathrm{Ge}_{n}{ }^{+}$is located from the first element $(1 \rightarrow k)$ in the last column $(2 n+2)$ of the working matrix. The peaks of the molecular ion cluster are placed in the last $(2 n+2-k \rightarrow 2 n+2)$ elements of the first column (0). Empty elements in the working matrix are filled with zeros. The completed matrix is shown in Scheme 2.

2. The coefficients of the columns [M, $(\mathrm{M}-\mathrm{H}),(\mathrm{M}-2 \mathrm{H})$, etc.] are $a_{0}, a_{1}, a_{2} \ldots$ up to $a_{(2 n+2)}$, respectively. The sum $\sum_{i=0}^{2 n+2} a_{i}=1$, and the weight of each component is constant for peaks in the cluster. The matrix is transformed into a vector $\left(P_{\text {calc. }} \rightarrow P_{\mathrm{H}}\right)$ by adding all of the terms located in the same row.

3 . The predicted pattern mentioned above is finally normalized to $100 \%\left(P_{\mathrm{H}} \rightarrow P_{\text {model }}\right)$. The experimental intensities are then compared with the intensities of the respective signals of the model $\left(P_{\exp } \leftrightarrow P_{\text {model }}\right)$ :

$$
\left.\begin{array}{c}
m_{1} \\
m_{2} \\
m_{3} \\
\vdots \\
m_{t-2} \\
m_{t-1} \\
m_{t} \\
P_{\text {exp. } 2} \\
P_{\text {exp. } 3} \\
\vdots \\
P_{\text {exp. }(\mathrm{t}-2)} \\
P_{\text {exp.t }}
\end{array}\right] \leftrightarrow\left[\begin{array}{c}
P_{\text {model.1. }} \\
P_{\text {model. } 2} \\
P_{\text {model. } 3} \\
P_{\text {model. }} \\
\vdots \\
P_{\text {model.(w-3) }} \\
P_{\text {model.(w-2) }} \\
P_{\text {model.(w-1) }} \\
P_{\text {model.w }}
\end{array}\right] \begin{gathered}
m_{1} \\
m_{w-3} \\
m_{w-2} \\
m_{w} \\
m_{w} \\
m_{w}
\end{gathered}
$$

Scheme 3

The accordance level is estimated using the model variance $s^{2}$ model calculated for the number $v$ of peaks that 
occur simultaneously in both the theoretical and the experimental bands:

$$
s_{\text {model }}^{2}=\frac{1}{v} \sum_{i=1}^{v}\left(P_{\text {exp.i }}-P_{\text {model.i }}\right)^{2}
$$

The part parameters $a_{0}, a_{1}, \ldots$ up to $a_{(2 n+2)}$ of the quasimolecular pattern model are varied until the minimal value of $s^{2}$ model is reached. The calculations involve predicting the number of components that form the experimental cluster as well as the values of the $a_{i}$ factors that describe the ion contributions to the experimental mass cluster. The procedure presented here involves the joint use of numerical and graphical methods, which solves the problem of local minima and simplifies the determination of the quasi-molecular cluster components. The calculation is continued until the smallest possible value of $s^{2}$ model is obtained, and until the best overlap between the model and the experimental clusters is reached. This procedure yields the best agreement of the model with the experimental data. The adjustment level is also determined as an accordance factor $\alpha$, given by the formula

$$
\alpha=\frac{s_{\text {theor }}^{2}-s_{\text {model }}^{2}}{s_{\text {theor }}^{2}} \times 100 \%
$$

The factor $\alpha$ provides a measure of the adjustment between the model and the experimental clusters. It estimates the agreement between the complex dehydrogenation model and the published (or experimental) molecular pattern. The real accuracy of the method is ca. $\pm 3 \%$.

All the possibilities were tested, up to eliminating hydrogen from the formula. The dehydrogenation calcula- tions [1] were applied, but all possible ions (from $\mathrm{Ge}_{n} \mathrm{H}_{2 n+2}{ }^{+}$ up to $\mathrm{Ge}_{n}{ }^{+}$) and variable components were examined. Good agreement (above 95\%) was obtained with models as simple as the three-component ones. Surprisingly, all appropriate models included the same three components: the molecular ion $\mathrm{Ge}_{n} \mathrm{H}_{2 n+2}{ }^{+}$, and two products of highly effective hydrogen elimination, the cations $\mathrm{Ge}_{n} \mathrm{H}^{+}$and $\mathrm{Ge}_{n}{ }^{+}$. The more complex models are slightly better, but the three-component one presented here gives satisfactory results (see, e.g., Figure 1, as well as Table 1). The results of more complex predictions failed to produce a significantly better fit to the experimental data. The three-component model is adequate for the elucidation of these mass spectral clusters.

\section{Discussion}

The relatively small improvement in the adjustment factor $\alpha$ obtained when the more complex models were used instead of models with three components shows that it is ineffective to use models with more than three components. This fact is highly unexpected. Is the existence of $\mathrm{Ge}_{n}{ }^{+}$and $\mathrm{Ge}_{n} \mathrm{H}^{+}$ions possible? Are these ions sufficiently stable to be registered in mass spectra?

Features of germanium such as variable valence (II and/or IV), potential for catenation, and the ability to form ions of cyclic and $3 \mathrm{D}$ structures may provide the basis for the occurrence of $\mathrm{Ge}_{n}^{+}$and $\mathrm{Ge}_{n} \mathrm{H}^{+}$ions in experimental mass spectra. Nevertheless, the determination of $\mathrm{Ge}_{n} \mathrm{H}^{+}$and $\mathrm{Ge}_{n}{ }^{+}$ ions in common EI mass spectra is indeed a surprise. The same species can arise in Knudsen effusion mass spectrometry and in standard electron ionization. The calculations presented here indicate that this is actually the case. The electron ionization of simple germanes runs to high levels of dehydrogenation. The results reveal a tendency for the mass spectra of higher hydrides

\begin{tabular}{|c|c|c|c|c|c|c|c|c|c|c|c|c|c|}
\hline & \multirow[t]{2}{*}{ Peaks } & \multicolumn{2}{|c|}{ LAPIC (u) } & \multirow[t]{2}{*}{$s_{\text {theor }}^{2}$} & \multirow{2}{*}{$\frac{\mathrm{Ge}_{n} \mathrm{H}_{2 n+2}{ }^{+}}{\text {(u) }}$} & \multirow[t]{2}{*}{$\mathrm{Ge}_{n} \mathrm{H}_{2 n+1}^{+}$} & \multirow[t]{2}{*}{$\mathrm{Ge}_{n} \mathrm{H}_{2 n-1}^{+}$} & \multirow[t]{2}{*}{$\mathrm{Ge}_{n} \mathrm{H}_{3}^{+}$} & \multirow[t]{2}{*}{$\mathrm{Ge}_{n} \mathrm{H}_{2}^{+}$} & \multirow[t]{2}{*}{$\mathrm{Ge}_{n} \mathrm{H}^{+}$} & \multirow[t]{2}{*}{$\mathrm{Ge}_{n}^{+}$} & \multirow[t]{2}{*}{$s_{\text {model }}{ }^{2}$} & \multirow{2}{*}{$\frac{\alpha}{(\%)}$} \\
\hline & & Calc. & Exp. & & & & & & & & & & \\
\hline \multirow[t]{4}{*}{$\mathrm{Ge}_{2} \mathrm{H}_{6}$} & 14 & 151 & 145 [17] & 1341 & 27 & & & & & & 73 & & 82.1 \\
\hline & & & & & 22 & & & & & 21 & 57 & 55.4 & 95.9 \\
\hline & & & & & 20 & & & 12 & & 11 & 57 & & 97.9 \\
\hline & & & & & 19 & 8 & & 1 & & 14 & 58 & & 98 \\
\hline \multirow{4}{*}{$\mathrm{Ge}_{3} \mathrm{H}_{8}$} & 25 & 226 & 219 [18] & 2306 & 34 & & & & & & 66 & & 97.9 \\
\hline & & & & & 25 & & & & & 38 & 37 & 46.0 & 98.0 \\
\hline & & & & & 24 & & & & 14 & 40 & 22 & & 98.5 \\
\hline & & & & & 22 & & & 18 & 3 & 23 & 34 & & 99.7 \\
\hline \multirow[t]{7}{*}{$\mathrm{Ge}_{4} \mathrm{H}_{10}$} & 33 & 300 & 292 [19] & 1768 & 25 & & & & & & 75 & & 91.6 \\
\hline & & & & & 21 & & & & & 27 & 52 & 10.8 & 99.4 \\
\hline & & & & & 18 & & & & 10 & 30 & 42 & & 99.5 \\
\hline & & & & & 18 & & & 3 & 10 & 25 & 44 & & 99.7 \\
\hline & & & & & 23 & & & & 7 & 24 & 46 & & 99.8 \\
\hline & & & & & 17 & & 4 & & 11 & 26 & 42 & & 99.8 \\
\hline & & & & & 20 & & 1 & 2 & 10 & 23 & 44 & & 99.9 \\
\hline \multirow[t]{4}{*}{$\mathrm{Ge}_{5} \mathrm{H}_{12}$} & 37 & 376 & 364 [20] & 1972 & 19 & & & & & & 81 & & 95 \\
\hline & & & & & 17 & & & & & 28 & 55 & 10.0 & 99.5 \\
\hline & & & & & 16 & & & & 7 & 28 & 49 & & 99.9 \\
\hline & & & & & $\mathrm{Ge}_{\mathrm{n}} \mathrm{H}_{2 \mathrm{n}+2^{+}}$ & $\mathrm{Ge}_{\mathrm{n}} \mathrm{H}_{2 \mathrm{n}+1}^{+}$ & $\mathrm{Ge}_{\mathrm{n}} \mathrm{H}_{2 \mathrm{n}-1}^{+}$ & $\mathrm{Ge}_{\mathrm{n}} \mathrm{H}_{3}^{+}$ & $\mathrm{Ge}_{\mathrm{n}} \mathrm{H}_{2}^{+}$ & $\mathrm{Ge}_{\mathrm{n}} \mathrm{H}^{+}$ & $\mathrm{Ge}_{\mathrm{n}}^{+}$ & & $\alpha$ \\
\hline
\end{tabular}

Table 1. Modeling of germane quasi-molecular clusters 
to be dominated by the ions with the highest germanium content, resulting from the complete elimination of hydrogen.

These results illustrate how many new possibilities can be realized through the systematic mathematical analysis of mass spectra. It is hoped that the application of isotopomeric analysis will enable the disclosure of many scientific secrets hidden in electron ionization mass spectra.

\section{Open Access}

This article is distributed under the terms of the Creative Commons Attribution Noncommercial License which permits any noncommercial use, distribution, and reproduction in any medium, provided the original author(s) and source are credited.

\section{References}

1. Goraczko, A.J., Szymura, J.A.: Dehydrogenation processes and molecular clusters in mass spectra of organometallic and coordination compounds. Comput. Chem. 24, 585-594 (2000)

2. Martin, P.T., Schaber, H.: Mass spectra of Si, Ge, and Sn clusters. J. Chem. Phys. 83, 855-858 (1985)

3. Gingerich, K.A., Sai Baba, M., Schmude Jr., R.W., Kingcade Jr., J.E.: Atomization enthalpies and enthalpies of formation of $\mathrm{Ge}_{3}$ and $\mathrm{Ge}_{4}$ by Knudsen effusion mass, spectrometry. Chem. Phys. 262, 65-74 (2000)

4. Gingerich, K.A., Schmude, R.W., Sai Baba, M., Meloni, G.: Atomization enthalpies and enthalpies of formation of the germanium clusters, $\mathrm{Ge}_{5}, \mathrm{Ge}_{6}, \mathrm{Ge}_{7}$ and $\mathrm{Ge}_{8}$ by Knudsen effusion mass spectrometry. J. Chem. Phys. 112, 7443-7447 (2000)

5. Trinquier, G.: Double bonds and bridged structures in the heavier analogues of ethylene. J. Am. Chem. Soc. 112, 2130-2137 (1990)

6. Burton, G.R., Xu, C., Arnold, C.C., Neumark, D.M.: Photoelectron spectroscopy and zero electron kinetic energy spectroscopy of germanium cluster anions. J. Chem. Phys. 104, 2757-2753 (1996)

7. Sekiguchi, A., Lee, V.: Ya. Cage compounds of heavier group 14 elements. In: Rappoport, Z. (ed.) The Chemistry of Organic Germanium, Tin and Lead Compounds, vol. 2, pp. 939, 940-944, 949-956. Wiley, Chichester (2002)
8. Earley, C.W.: Ab initio investigation of strain in group 14 polyhedrane clusters $\left(\mathrm{M}_{n} \mathrm{H}_{n} ; n=4,6,8,10,12,14,16,20,24\right)$. J. Phys. Chem. A. 104, 6622-6627 (2000)

9. Saalfeld, F.E., Svec, H.J.: The mass spectra of volatile hydrides. I. The monoelemental hydrides of the group IVB and VB elements. Inorg. Chem. 2, 46-50 (1963)

10. Saalfeld, F.E., Svec, H.J.: The mass spectra of volatile hydrides. II. Some higher hydrides of the group IVB and VB elements. Inorg. Chem. 2, 50-53 (1963)

11. Chambreau, S.D., Zhang, J.: $\mathrm{GeH}_{x}(x=0-3)$ and $\mathrm{Ge}_{n} \mathrm{H}_{x}(n=2-7)$ in flash pyrolysis of $\mathrm{GeH}_{4}$. Chem. Phys. Lett. 351, 171-177 (2002)

12. Riveros, J.M., Takashima, K.: Gas-phase chemistry and mass spectrometry of Ge-, Sn- and Pb-containing compounds. In: Rappoport, Z. (ed.) The Chemistry of Organic Germanium, Tin and Lead Compounds, pp. 360-364. Wiley, Chichester (2002)

13. Ricca, A., Bauschlicher Jr., C.W.: Heats of formation for $\mathrm{GeH}_{n}(n=$ $1-4)$ and $\mathrm{Ge}_{2} \mathrm{H}_{n}(n=1-6)$. J. Phys. Chem. A. 103, 11121-11125 (1999)

14. Knight, L.B., Herlong, J.O., Babb, R., Earl, E., Hill, D.W., Arrington, C.A.: Matrix isolation electron spin resonance studies of ${ }^{28,}{ }^{28} \mathrm{Si}_{2}{ }^{+},{ }^{28}$, ${ }^{29} \mathrm{Si}_{2}{ }^{+},{ }^{29,}{ }^{29} \mathrm{Si}_{2}{ }^{+}, \mathrm{Ge}_{2}{ }^{+},{ }^{73} \mathrm{Ge}_{2}{ }^{+}$, produced by pulsed laser vaporization. Comparison with theoretical calculations. J. Phys. Chem. 95, 27322738 (1991)

15. $\mathrm{C}_{2} \mathrm{H}_{6}$ (ID\# 14864). In: Wiley $138 \mathrm{~K}$ Mass Spectral Database. John Wiley \& Sons, Inc., Hoboken (1990)

16. $\mathrm{C}_{3} \mathrm{H}_{8}$ (CAS\#: 14691-44-2; NIST\#: 37328; ID\#: 94940; contributor: Pinson, J.W., Univ. S. Mississippi, Hattiesburg, MS, USA). In: NIST2000 Mass Spectral Database. National Institute of Standards and Technology, Gaithersburg (2000)

17. $\mathrm{C}_{4} \mathrm{H}_{10}$ (CAS\#: 14691-47-5; NIST\#: 37397; ID\#: 94862; contributor: Pinson, J.W., Univ. S. Mississippi, Hattiesburg, MS, USA). In: NIST2000 Mass Spectral Database. National Institute of Standards and Technology, Gaithersburg (2000)

18. $\mathrm{C}_{5} \mathrm{H}_{12}$ (CAS\#: 15587-39-0; NIST\#: 37310; ID\#: 132180; contributor: Pinson, J.W., Univ. S. Mississippi, Hattiesburg, MS, USA). In: NIST2000 Mass Spectral Database. National Institute of Standards and Technology, Gaithersburg (2000)

19. Goraczko, A.J., Szymura, J.A.: The prediction of relative abundance of isotopic clusters in mass spectrometry of coordination and organometallic compounds. Comput. Chem. 23, 135-142 (1999)

20. Gorączko, A.J.: Modeling of isotopomeric molecular clusters in electron ionisation mass spectra. J. Mol. Model 13, 813-821 (2007) 